\title{
An experimental study of cathodic protection for chloride contaminated reinforced concrete
}

\author{
Hayder M. Oleiwi - Yu Wang (D) Michele Curioni - Xianyi Chen • \\ Guowen Yao $\cdot$ Levingshan Augusthus-Nelson • A. H. Ragazzon-Smith • \\ Igor Shabalin
}

Received: 22 March 2018/Accepted: 12 October 2018/Published online: 25 October 2018

(C) The Author(s) 2018

\begin{abstract}
Cathodic protection (CP) is being increasingly used on reinforced concrete structures to protect steel reinforcing bars from corrosion in aggressive conditions. Due to the complexity of environmental conditions, the design specifications in national and international standards are still open to discussion to achieve both sufficient and efficient protection for reinforced concrete structures in engineering practices. This paper reports an experimental research to investigate the influence of chloride content on concrete resistivity, rebar corrosion rate and the performance of $\mathrm{CP}$ operation using different current densities. It aims to understand the correlation between the chloride content and concrete resistivity together with the $\mathrm{CP}$ current requirement, and to investigate the precision of the $\mathrm{CP}$ design criteria in standards.
\end{abstract}

H. M. Oleiwi · Y. Wang ( $₫)$ · L. Augusthus-Nelson ·

I. Shabalin

School of Computing, Science and Engineering,

University of Salford, Manchester M5 4WT, UK

e-mail: y.wang@salford.ac.uk

M. Curioni

School of Materials, Corrosion and Protection Centre, University of Manchester, Manchester M13 9PL, UK

X. Chen

Charter Coating Service (2000) Ltd., Calgary,

AB T2E 6P1, Canada
Keywords Cathodic protection - Concrete resistivity $\cdot$ Reinforcement corrosion $\cdot \mathrm{CP}$ design criteria

\section{Introduction}

The corrosion of steel reinforcements has been recognised as the major cause for the premature deterioration of reinforced concrete structures worldwide [1]. Extensive researches on the deterioration mechanisms have concluded that the combined presence of chloride and the decrease in $\mathrm{pH}$ due to carbonation plays the most significant role in the corrosion of concrete reinforcements [2, 3]. So far, many technologies using chemical, mechanical, and electrochemical methods have been developed to address the problem [4, 5]. Among those, cathodic

\footnotetext{
A. H. Ragazzon-Smith

School of Environment and Life Sciences, University of Salford, Manchester M5 4WT, UK

G. Yao

School of Civil Engineering, Chongqing Jiaotong

University, Chongqing 400074, China

H. M. Oleiwi

College of Engineering, University of Thi-Qar, Nasiriyah, Iraq
} 
protection $(\mathrm{CP})$, has been widely recognised and become the most popular technique implemented in civil engineering practices for its reliable long term protection [6-8].

Adequate protection provided by $\mathrm{CP}$ for the steel reinforcement in concrete depends on many factors. In addition to the steel composition and the nature of concrete components, the physical conditions, such as concrete porosity, degree of carbonation, water and chloride contents, and environmental temperature, play the important roles affecting the effectiveness of $\mathrm{CP}$ operation. CP arrangement and the applied current densities are all related to the above conditions $[9,10]$. Additionally, the service life of the anode is another factor to be taken in consideration [11, 12]. Traditionally, titanium mesh sheet with noble metal oxides coating, such as iridium, ruthenium and cobalt, have been the most common type of anodes [12]. Other materials, offering ease of installation and cost efficiency, have also been employed [13]. In recent years, due to its good chemical stability, carbon fibre has been successfully used as anode material in CP implementation for concrete structures [13-15].

In general, there are two acceptable criteria in $\mathrm{CP}$ performance appraisal. One relates to the instant-off potential (the potential measured immediately when the CP system is switched off) of the reinforcement. The other one relates to the potential decay (depolarization) of the reinforcement $[16,17]$. The specifications in national and international standards for the criteria were principally established on the empirical evaluation of the data obtained from successfully operated CP cases [18]. For example, Takewaka [19] suggested that the corrosion of reinforcement in concrete structures could be stopped when the potential of the rebars was less than $-600 \mathrm{mV}$ with respect to $\mathrm{Ag} / \mathrm{AgCl} / 0.5 \mathrm{KCl}$ reference electrode. For chloridecontaminated concrete, more negative potentials in the range of -645 to $-705 \mathrm{mV}$ with respect to $\mathrm{Ag} /$ $\mathrm{AgCl} / 0.5 \mathrm{KCl}$ were reported by Shi et al. [20]. British standard 12696:2012 [21] specifies that the instant-off potential should be more negative than $-720 \mathrm{mV}$ with respect to $\mathrm{Ag} / \mathrm{AgCl} / 0.5 \mathrm{KCl}$ for any concrete structures. For the depolarization criterion, the widely adopted specification is that the reinforcement potential should decay (i.e. become less negative) by at least $100 \mathrm{mV}$ over a period of 4-24 $\mathrm{h}$ starting from an 'instant-off' potential [18, 21, 22].
Applying an adequate current density to ensure sufficient current across the critical areas of the protected reinforcement [11] but at a cost efficient energy consumption and without overprotection is vital to avoide unnecessary expenses and the potential negative effect of the hydrogen production due to the activated cathodic reactions at the rebar and concrete interface. No CP implementation can achieve an effective protection using a specified constant current density throughout the life span of concrete structures [16]. A previous work suggested that, for newly built concrete structures, a current density in the range of $1-2 \mathrm{~mA} / \mathrm{m}^{2}$ on the rebars is sufficient for protection, while for the structures that have already suffered from reinforcement corrosion, a current density in the range of $5-20 \mathrm{~mA} / \mathrm{m}^{2}$ is recommended [23]. Higher practical CP current densities in the range of $30-50 \mathrm{~mA} / \mathrm{m}^{2}$ were also suggested when reinforcements are exposed to severe environmental conditions [16].

Based on the discussion above, it is noted that some uncertainty still exist on the topic of defining the current specification for $\mathrm{CP}$ design for reinforced concrete structures for varied and complex application conditions. As an effort to obtain more detailed specific information for the $\mathrm{CP}$ design for chloride contaminated reinforced concrete structures, this paper reports an experimental study on the effect of concrete chloride contamination degree on the corrosion evaluation parameters that are employed for reinforcement cathodic protection assessment. Specifically, this work investigates the correlation between the chloride content and concrete resistivity, and the relationship of these two parameters with the rebar corrosion rate. These studies enable identification of more precise characteristic relationships between concrete chloride content, the applied current density and the instant-off potential. Thus, the experimental results provide a direct guidance for the specification of the CP current density requirements for atmospherically exposed concrete structure at different levels of chloride contamination.

\section{Specimens preparation}

Concrete specimens used in this study were prepared following the method recommended by the British Building Research Establishment (BRE) [24] to give a 28 days compressive strength of $38 \mathrm{~N} / \mathrm{mm}^{2}$. Locally 
produced limestone Portland cement (CEM II/A-LL in British standard BS EN 197-1: 2011) was used at $390 \mathrm{~kg} / \mathrm{m}^{3}$. Natural sands of the maximum size of $4.75 \mathrm{~mm}$ and a specific gravity of 2.47 were used for the fine aggregates at $1125 \mathrm{~kg} / \mathrm{m}^{3}$. The coarse aggregates were limestone of maximum size of $10 \mathrm{~mm}$ and a specific gravity of 2.49 , and were used at $580 \mathrm{~kg} / \mathrm{m}^{3}$ in proportion. Pure $\mathrm{NaCl}(0,1,2,3.5$, and $5 \%$ of the cement weight) was added as contaminant into the mix water, to prepare specimens with different chloride contamination contents. The concrete mixes had a water to cement ratio of 0.4 .

Ten reinforced concrete specimens ( 2 specimens for each chloride content) with the size of Length $\times$ Height $\times$ Depth $=90 \times 93 \times 150 \mathrm{~mm}^{3}$, illustrated in Fig. 1, were used to investigate the CP operation. Each specimen had three conventional reinforcing bars of $10 \mathrm{~mm}$ diameter to simulate local rebar clusters in structures. On the other hand, considering that the rebars' position in concrete affects the corrosion rate due to differences in oxygen access, taking an average response of the three electrically connected rebars aims to minimize the influence of location on the final results. A hole of $3 \mathrm{~mm}$ in diameter and $5 \mathrm{~mm}$ in depth was drilled at one end of each rebar. One end of a copper wire used for electrical connection and it was soldered into the hole for fully integrated contact. The two ends of all the steel rebars were coated using epoxy resin to prevent direct exposure to the environment when embedded in concrete specimens. The middle region of an effective length $73 \mathrm{~mm}$ along the rebar axis was directly exposed to the concrete environment to give a total exposed surface area of $3 \pi \times 10 \times 73=6880 \mathrm{~mm}^{2}$.
A layer of a woven (CF) sheet was embedded in each specimen to be used as the anode. The nominal surface area of the embedded carbon fibre anode is $144 \times 93 \mathrm{~mm}^{2}$. The carbon fibre anode extended about $30 \mathrm{~mm}$ out of the specimens for electrical connection. All the cast reinforced concrete specimens had the entire part of the steel bars exposed to the atmosphere coated again using epoxy resin after the concrete set.

Another ten rectangular concrete specimens of the size of Length $\times$ Height $\times$ Depth $=100 \times 100 \times$ $70 \mathrm{~mm}^{3}$ and with two parallel embedded woven carbon fibre (CF) sheets as shown in Fig. 2, were prepared for concrete resistivity measurement using the same mixtures and the curing procedure as that of the reinforced concrete specimens described above. The two woven carbon fibre sheets are used for the electrodes, which were kept a fixed distance of $55 \mathrm{~mm}$ from each other and held in the upright position using two rigid perforated plastic plates in moulds when cast the concrete specimens [25].

All the prepared concrete specimens were placed in water with the same chloride concentration as that of the mix water used and cured for 28 days. Such method aims to ensure an even chloride distribution. Thereafter all concrete specimens were taken out and exposed to an atmosphere of a relative humidity of $50 \pm 5 \%$ and a temperature of $20 \pm 3{ }^{\circ} \mathrm{C}$ for 5 weeks, i.e. until they attained a stable weight before conducting all the experiments. To obtain the accurate total chloride contents in the specimens, another ten concrete specimens of all the same mixtures (two specimens for each designed chloride content) with the size of $100 \times 100 \times 100 \mathrm{~mm}^{3}$ and cured in the
Fig. 1 The configuration and dimension of the reinforced concrete specimens

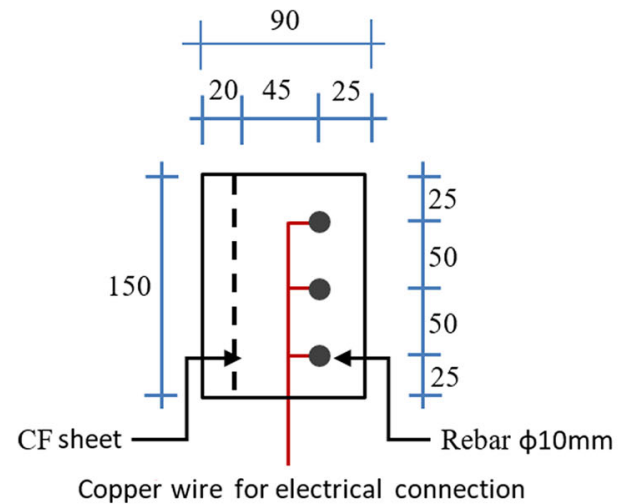

Top view

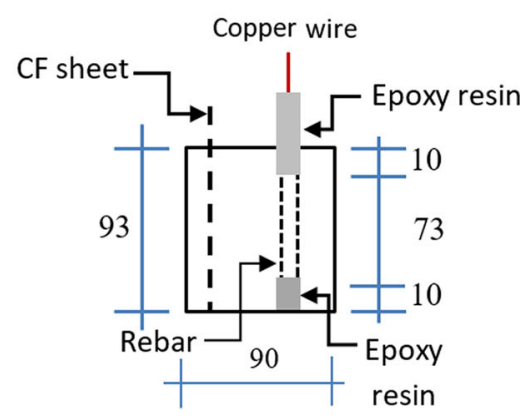

Side view 


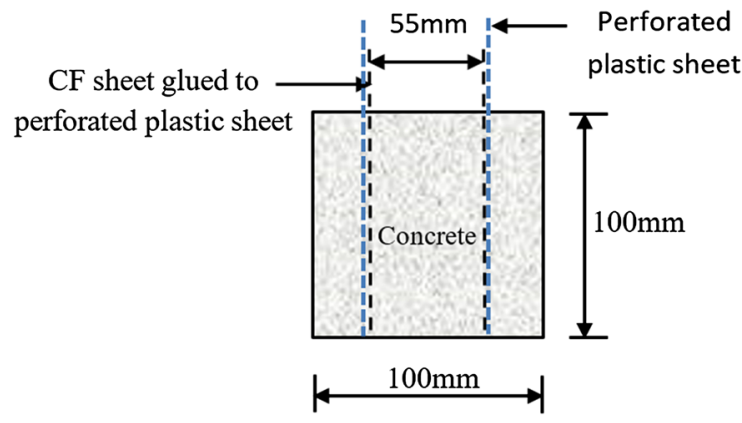

Fig. 2 Illustration of concrete specimens used for electrical resistivity measurements

same conditions were analysed using potentiometric titration method described in ASTM C1152/C1152M12 [26].

\section{Experimental methods}

\subsection{Corrosion rate and concrete electrical resistivity}

The corrosion rates of rebars in the reinforced concrete specimens were assessed before the implementation of $\mathrm{CP}$ using the linear polarization method described by Stern and Geary [27]. The potential of the three reinforcing bars were acquired together through the soldered wires. The corrosion rate of the three rebars was measured in terms of the average current density, $i_{\text {corr }}$. A small potential shift, $\Delta E$, was applied on rebars of an open circuit potential, $E_{\text {corr }}$. The potential shift varied from -20 to $+20 \mathrm{mV}[28,29]$ at a scan rate of $0.125 \mathrm{mV} / \mathrm{s}$ using a computer controlled Gamry potentiostat (Model 1000E). The IR drop was automatically compensated by the programmed potentiostat.

Polarization resistance, $R_{\mathrm{p}}$, was then determined according to the slope of the plot of the applied voltage versus the measured current at the point of zero current. The same method was applied for all the specimens for the sake of comparison [30]. The corrosion current was determined following the SternGeary equation,

$I_{\text {corr }}=\frac{B}{R_{\mathrm{p}}} \times 10^{-3}$, where $B=\left(\beta_{a} \beta_{c} / 2.3\left(\beta_{a}+\beta_{c}\right)\right)$ is a constant in $\mathrm{mV}, \beta_{a}$ and $\beta_{c}$ are the anodic and cathodic Tafel constants, $R_{\mathrm{p}}$ is the polarization resistance in $\mathrm{k} \Omega(\Delta E / \Delta I), I_{\text {corr }}$ is the corrosion current in $\mathrm{mA}$.

A value of $26 \mathrm{mV}$ was used for the constant $B$ for the chloride contaminated specimens $[6,31]$ while $52 \mathrm{mV}$ was used for the chloride free specimens. The corrosion rate, $i_{\text {corr }}$, in $\left(\mathrm{mA} / \mathrm{m}^{2}\right)$ is determined in terms of the Eq. (2) [32], where $A$ was the total exposure surface area of all the three rebars in a specimen.

$i_{\text {corr }}=\frac{I_{\text {corr }}}{A}$.

Concrete electrical resistivity was measured using the two-electrode specimens (Fig. 2). A sinewave alternating current of $3000 \mathrm{mV}$ amplitude and a frequency of $10 \mathrm{kHz}$ was applied across the two parallel electrodes. The electrical resistivity of the concrete was calculated in terms of the revised form of Ohm's law below [33].

$\rho=\frac{V}{I} \frac{A}{L}$,

where $\rho$ is electrical resistivity, $V$ is the amplitude of the applied voltage, $I$ is the amplitude of the measured current, $\mathrm{A}$ is the cross-section area of the concrete specimen perpendicular to the current flow or parallel to the two electrode plates, and L is the distance between the two electrodes.

\subsection{Cathodic protection}

Galvanostatic polarization technique was adapted to apply ten different $\mathrm{CP}$ current densities on the rebars in each specimen. They are 5, 10, 15, 20, 25, 35, 45, 55, 65 , and $75 \mathrm{~mA} / \mathrm{m}^{2}$, respectively. Ten specimens (two for each chloride content) were connected in series in each test at the same time as shown in Fig. 3. Silver/ Silver chloride $(\mathrm{Ag} / \mathrm{AgCl} / 0.5 \mathrm{KCl})$ half cells were used for the reference electrodes. Multi-channel data logger with $10,000 \mathrm{k} \Omega$ input impedance and $0.1 \mathrm{mV}$ resolution was used for the collection of all potential readings.

Each test had a certain CP current density applied for $24 \mathrm{~h}$ and afterwards switched off for more than one day $(24 \mathrm{~h})$ to ensure a sufficient depolarization of the rebars. In the time, the potential of rebars was continuously recorded from the start and until $4 \mathrm{~h}$ 
after the interruption of the CP current in the time of depolarization. Based on the recorded data, the instant-off potential, and 4-h potential decay can be obtained.

\section{Results and discussion}

\subsection{Chloride contents, corrosion rate and concrete resistivity}

The measured chloride contents in the cured specimens of each mixes with different added $\mathrm{NaCl}$ and the corresponding electrical resistivity of the concrete are listed in the Table 1. Chloride contents are expressed in term of the percentage of the cement weight of specimens.

Figure 4 shows the correlation between the corrosion rate and chloride content and the corresponding concrete electrical resistivity for these specimens. It can be clearly seen that the higher chloride content or the lower the concrete resistivity, the higher the reinforcement corrosion rate. Previous research [34] suggested that corrosion risk is considered to be low when corrosion rate is in the range of $1-5 \mathrm{~mA} / \mathrm{m}^{2}$, moderate when in the range of $5-10 \mathrm{~mA} / \mathrm{m}^{2}$, and high when greater than $10 \mathrm{~mA} / \mathrm{m}^{2}$. In terms of the classification, reinforcements will have a low corrosion rate if the total chloride content is less than $0.45 \%$ by the mass of cement and this chloride content may be taken as a threshold for the risk posed by reinforcement corrosion. If chloride content is over $1.4 \%$, reinforcements present a high corrosion rate. The threshold

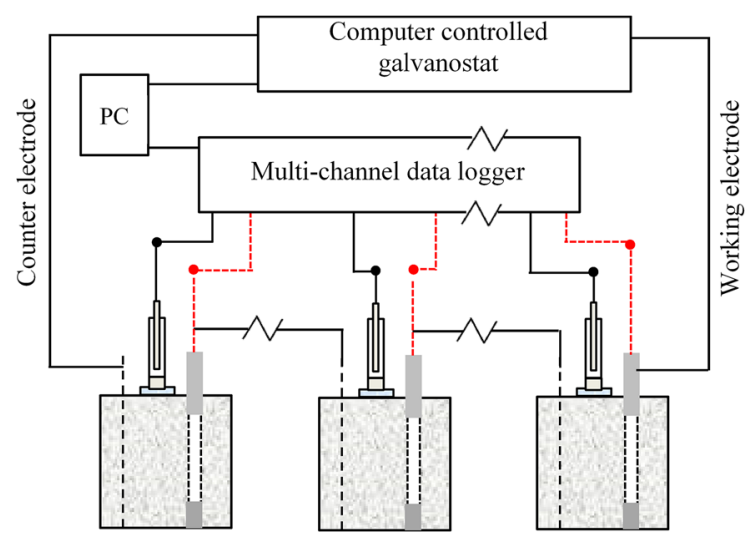

Fig. 3 Experimental scheme for reinforced specimens under $\mathrm{CP}$ value is in agreement with that recommended in literature [35], in which the critical chloride content was suggested in the range of $0.4-1 \%$ by weight of cement. In terms of concrete electrical resistivity, Fig. 4 shows that reinforcements will are likely to experience a low corrosion rate if the concrete electrical resistivity is higher than $17 \mathrm{k} \Omega \mathrm{cm}$, or a high corrosion rate if the concrete resistivity is less than $12.5 \mathrm{k} \Omega \mathrm{cm}$. The result is in agreement with previous research. For example, an earlier study [36] concluded that very high corrosion occurred when resistivity was less than $10 \mathrm{k} \Omega \mathrm{cm}$. Based on an investigation of the corrosion damage in a highway bridge, Cavalier and Vassie [37] also concluded that corrosion is almost certainly occurring when concrete resistivity is below $5 \mathrm{k} \Omega \mathrm{cm}$, but it is generally insignificant for values of resistivity above $12 \mathrm{k} \Omega \mathrm{cm}$. Another study considered that the risk of corrosion is negligible when resistivity exceeds $20 \mathrm{k} \Omega \mathrm{cm}$ but becomes very high when resistivity is lower than $5 \mathrm{k} \Omega \mathrm{cm}[38,39]$.

\subsection{The effect of CP operation time on instant-off potential}

The potential of the reinforcements instantly after the interruption of CP is called the instant-off potential which, in the present study, was automatically measured in $1 \mathrm{~s}$ after the CP was switched off $[18,21]$. Figure 5 shows the variation of the instant-off potential of the reinforcements as a function of the time of $\mathrm{CP}$ operation under different protection current densities for the specimens with $1 \%$ added $\mathrm{NaCl}$. For the case of $20 \mathrm{~mA} / \mathrm{m}^{2}$, the measurement were conducted for up to $120 \mathrm{~h}$ (5 days), while for the other two cases the measure were interrupted after $25 \mathrm{~h}$. It can been seen that, for all the three cases, the instant-off potential displays a significant change in the first $3 \mathrm{~h}$ of CP operation under all the applied current densities. After $3 \mathrm{~h}$, all the curves become flat, showing a very slight variation with time, suggesting that the system had reached a stable state. According to the results in the Fig. 5, all the parameters used for CP performance assessment, in this study, were taken after $24 \mathrm{~h}$ on $\mathrm{CP}$ implementation. 
Table 1 Chloride content, reinforcement corrosion rate and concrete resistivity

\begin{tabular}{|c|c|c|c|c|c|}
\hline Added $\mathrm{NaCl} \%$ cement weight & 0 & 1 & 2 & 3.5 & 5 \\
\hline Measured total $\mathrm{Cl}^{-} \%$ cement weight & 0 & 0.814 & 1.425 & 2.258 & 3.301 \\
\hline Concrete resistivity $\mathrm{k} \Omega \mathrm{cm}$ & 18.4 & 15.9 & 12.4 & 10.1 & 7.7 \\
\hline
\end{tabular}

Fig. 4 Reinforcement corrosion rate versus chloride contents and concrete resistivity

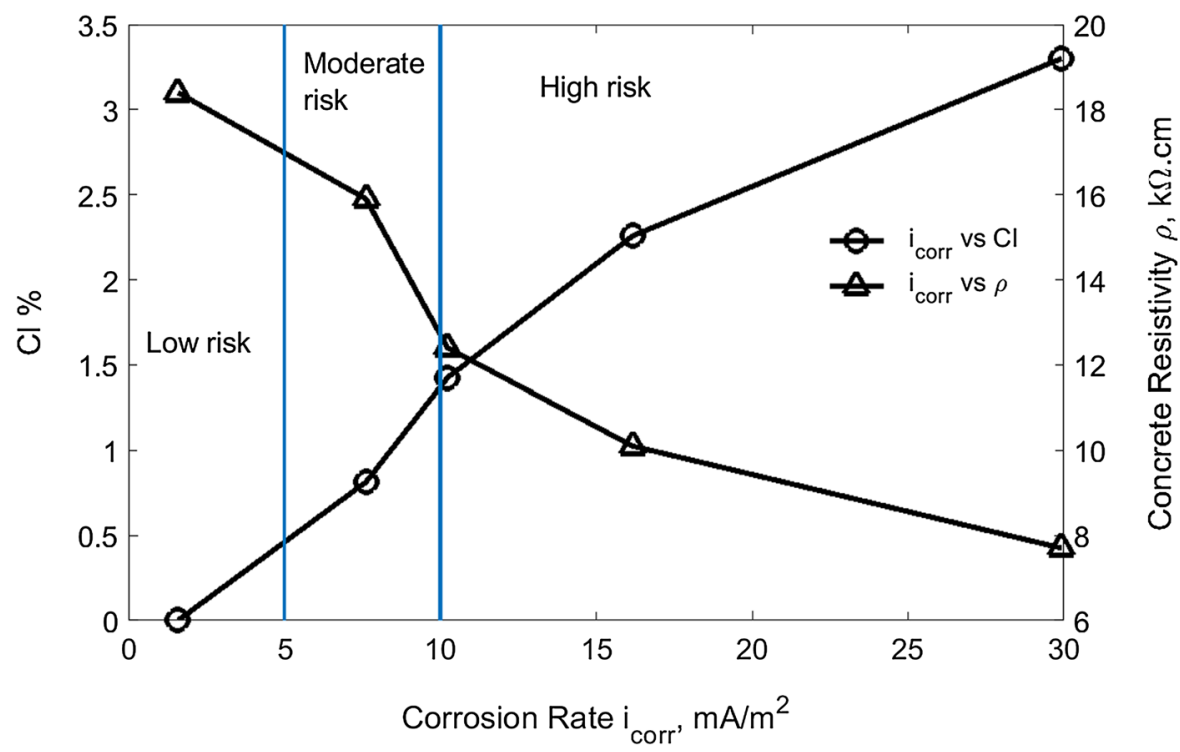

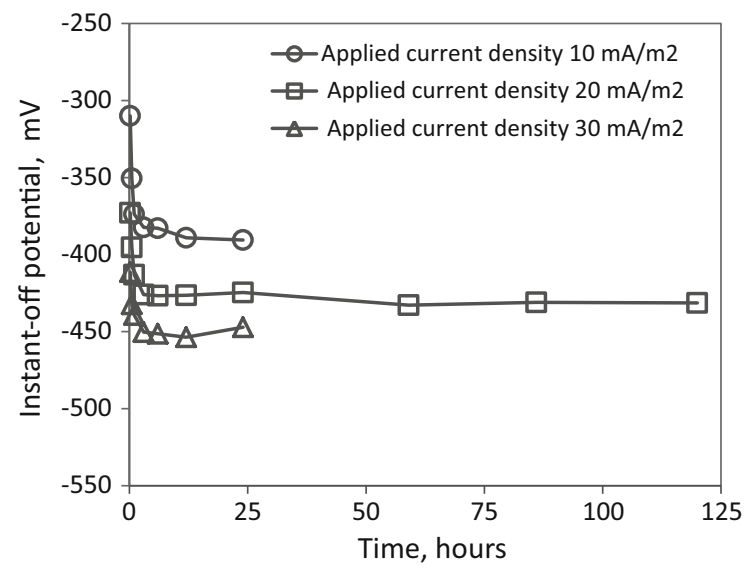

Fig. 5 Reinforcement instant-off potential versus $\mathrm{CP}$ operation time

\subsection{Effects of $\mathrm{CP}$ current density and chloride content on instant-off potential}

Instant-off potential is one of the important criteria used to evaluate CP performance [18], for example the $-720 \mathrm{mV}$ is recommend in British standard [21].
Figure 6 shows the variation of the $24 \mathrm{~h} \mathrm{CP}$ instant-off potential of the reinforcements in the specimens of different chloride contents under different $\mathrm{CP}$ current densities. It can be seen that the absolute value of instant-off potential increases with the increase of the applied CP current density, the slope of the curve become flat when the concrete chloride content increases. From the result, it can be seen that even at the highest applied current density (i.e., $75 \mathrm{~mA} / \mathrm{m}^{2}$ ) for all the different chloride contaminated specimens the $-720 \mathrm{mV}$ criterion is still far away to be achieved.

\subsection{4-h potential decay}

The potential difference between the instant-off potential and the potential measured at the $4 \mathrm{~h}$ after switching off the CP current is called the 4-h potential decay which is another important parameter used to evaluate the effectiveness of CP operation [40, 41]. Generally, $100 \mathrm{mV}$ depolarization in a $4 \mathrm{~h}$ period of time is the most accepted criterion. Figure 7 shows the variation of reinforcement depolarization (4-h 


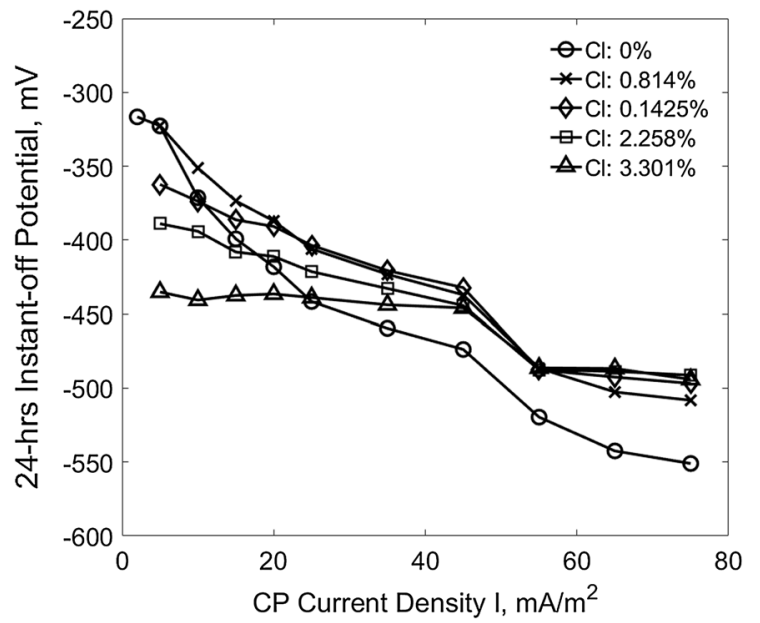

Fig. 6 24-h instant-off potential versus CP current density at different chloride contents

potential decay) against the applied CP current density at different chloride contamination. It can be seen that for a certain chloride content, the depolarization of the reinforcements increases with the increase of the applied current density. For chloride free specimens, the 4-h potential decay curve is in the region above $100 \mathrm{mV}$ (the horizontal solid line). It indicates that the reinforcements in a chloride free concrete environment are safe from corrosion even without $\mathrm{CP}$ (i.e., $I=0$ ). Comparing the Figs. 6 and 7, it can be clearly noticed that, for example, a current density about $15 \mathrm{~mA} / \mathrm{m}^{2}$ is sufficient to provide the required protection for the reinforcement in the concrete of $0.814 \%$ chloride in terms of the $100 \mathrm{mV}$ potential decay criterion. However, current density of $75 \mathrm{~mA} /$ $\mathrm{m}^{2}$ is not enough to protect the reinforcement even in chloride free concrete in terms of the $-720 \mathrm{mV}$ instant-off potential criterion.

Figure 8 compares the two conventional criterion parameters, i.e., the $24 \mathrm{~h} \mathrm{CP}$ instant-off potential and 4-h potential decay at different $\mathrm{CP}$ current density in terms of the results in Figs. 6 and 7. It shows that in terms of the $100 \mathrm{mV}$ 4-h potential decay criterion, - $500 \mathrm{mV}$ 24-h CP instant-off potential is sufficient to protect the reinforcements in all the investigated contaminated concretes.

Figure 9 shows the required current densities for $100 \mathrm{mV}$ (the interception points on the horizontal solid line in Fig. 7) and $50 \mathrm{mV}$ (the interception points on the horizontal dash line in Fig. 7) depolarization (the 4-h potential decay) for the reinforcements at

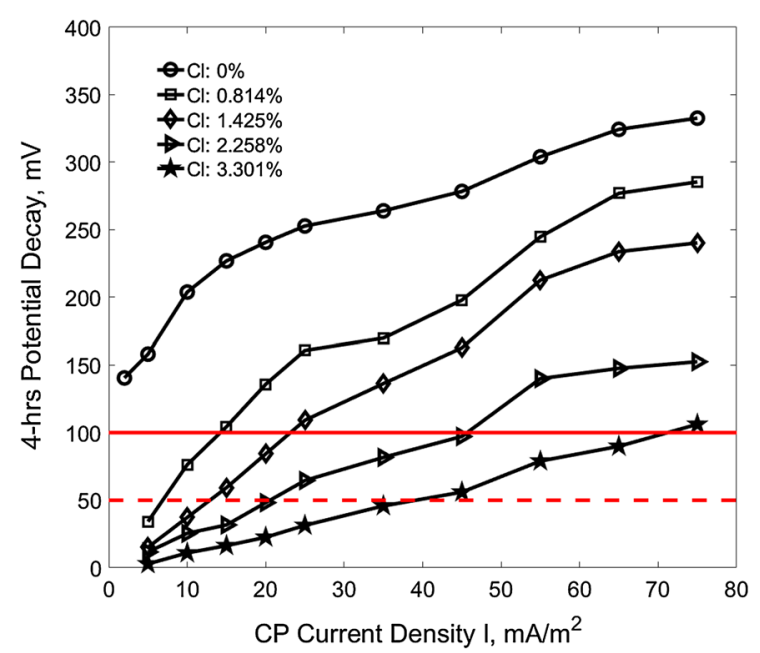

Fig. 7 Reinforcement depolarization versus CP current density (the horizontal solid line for the criterion of $100 \mathrm{mV}$ and the dash line for $50 \mathrm{mV}$ )

different initial corrosion rates before $\mathrm{CP}$ operation. The dash-dot line indicates the condition when the applied CP current density equals to the initial corrosion rate of the reinforcements. It can be seen that the suggested protection current density in terms of the $100 \mathrm{mV}$ depolarization criterion is much higher than the corrosion rate of reinforcements. Particularly, the extra protection current density is projected at a high CP current density when reinforcement exposes to high chloride contamination or has a high initial corrosion rate. However, the $\mathrm{CP}$ current density in

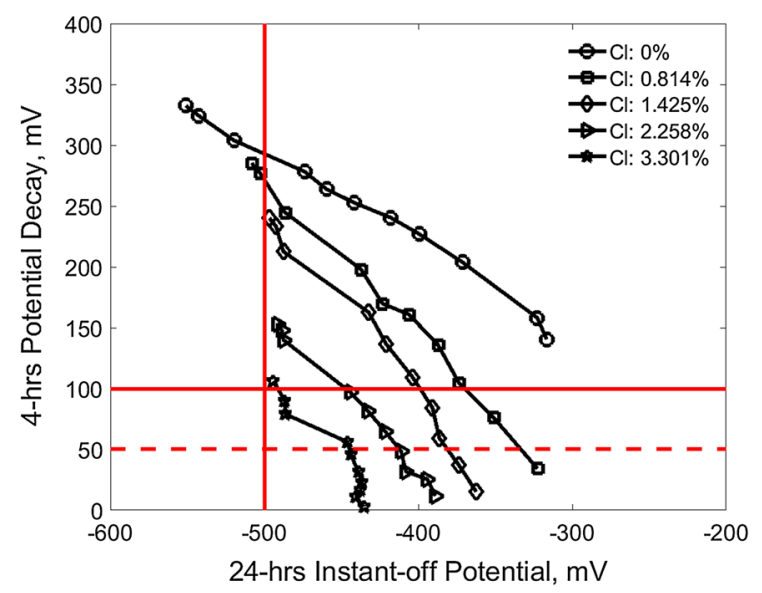

Fig. 8 Reinforcement depolarization versus CP current density and 24-h CP instant-off potential (the horizontal solid line for $100 \mathrm{mV}$ potential decay and the dash line for $50 \mathrm{mV}$ while the vertical solid line for $-500 \mathrm{mV}$ instant-off potential) 


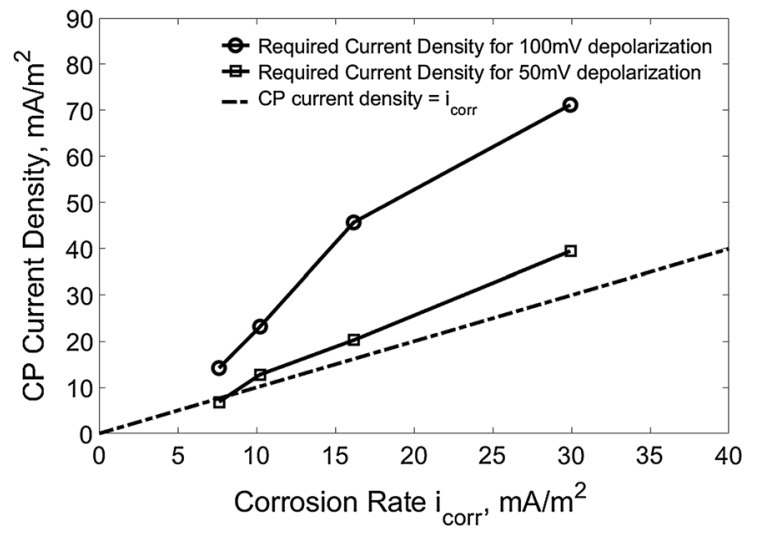

Fig. 9 The required CP current density for different depolarization versus the initial corrosion rate of reinforcements

terms of the $50 \mathrm{mV}$ depolarization condition is very close to the dash-dot line at all reinforcement initial corrosion rates.

Figure 10 shows the CP current densities which give the $100 \mathrm{mV}$ and $50 \mathrm{mV}$ depolarization (the 4-h potential decays) for the reinforcements in the concrete of different chloride content and the corresponding electrical resistivity. The data are the interception points of all the curves in the Fig. 7 on the solid horizontal line at $100 \mathrm{mV}$ and the dash horizontal line at $50 \mathrm{mV}$ 4-hrs potential decay. It can be seen that the required CP current density for both of the 100 and $50 \mathrm{mV}$ depolarization present an approximately linear correlation to the chloride content. A linear correlation to the concrete resistivity can also be assumed for practical purpose as well. According to the results, there is no CP needed when chloride content is less than about $0.31 \%$, a value about $75 \%$ of the $0.45 \%$ the upper limit for low risk that was discussed in the Sect. 4.1 before according to the classification of Broomfield [34], or when concrete resistivity is more than about $17 \mathrm{k} \Omega \mathrm{cm}$.

Similarly, Fig. 11 shows the 24-h CP instant-off potential which corresponds to the $100 \mathrm{mV}$ and $50 \mathrm{mV}$ depolarization (the 4-h potential decay) for the reinforcements in the concrete of different chloride content and the corresponding electrical resistivity. The data are the interception points of all the curves in the Fig. 8 on the solid horizontal line at $100 \mathrm{mV}$ and the dash horizontal line at $50 \mathrm{mV}$ depolarization. It also demonstrates that the required instant-off potential for both of the 100 and $50 \mathrm{mV}$ depolarization can also be approximately characterised using linear correlation to both the chloride content and concrete resistivity, respectively. It can be seen that $-500 \mathrm{mV}$ instant-off potential can provide adequate protection for the reinforcement in concrete of up to $3.4 \%$ chloride content or of more than $6.7 \mathrm{k} \Omega \mathrm{cm}$ resistivity in terms of the $100 \mathrm{mV}$ potential decay criterion. However, taking $50 \mathrm{mV}$ potential decay as a criterion, the $-500 \mathrm{mV}$ instant-off potential can provide sufficient protection for the chloride content up to $4.5 \%$ or concrete resistivity less than $3.8 \mathrm{k} \Omega \mathrm{cm}$.

Finally, for the results obtained in this study, there are two specific concerns that should be clarified:

1. The initial formation of passive layer was not taken into account, as chloride was added into the mix water to accelerate corrosion. Without considering the initial passivation, the measurement
Fig. 10 The required CP current density for the $100 \mathrm{mV}$ and $50 \mathrm{mV}$ depolarization versus chloride content and concrete resistivity (the horizontal lines indicate no CP current)
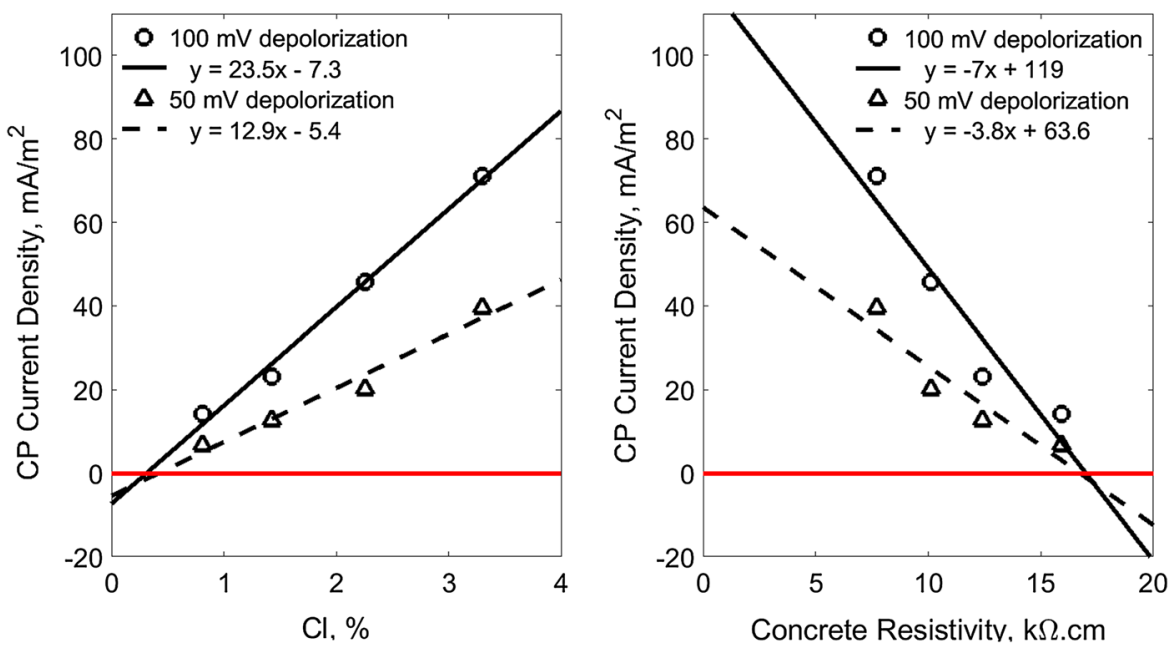

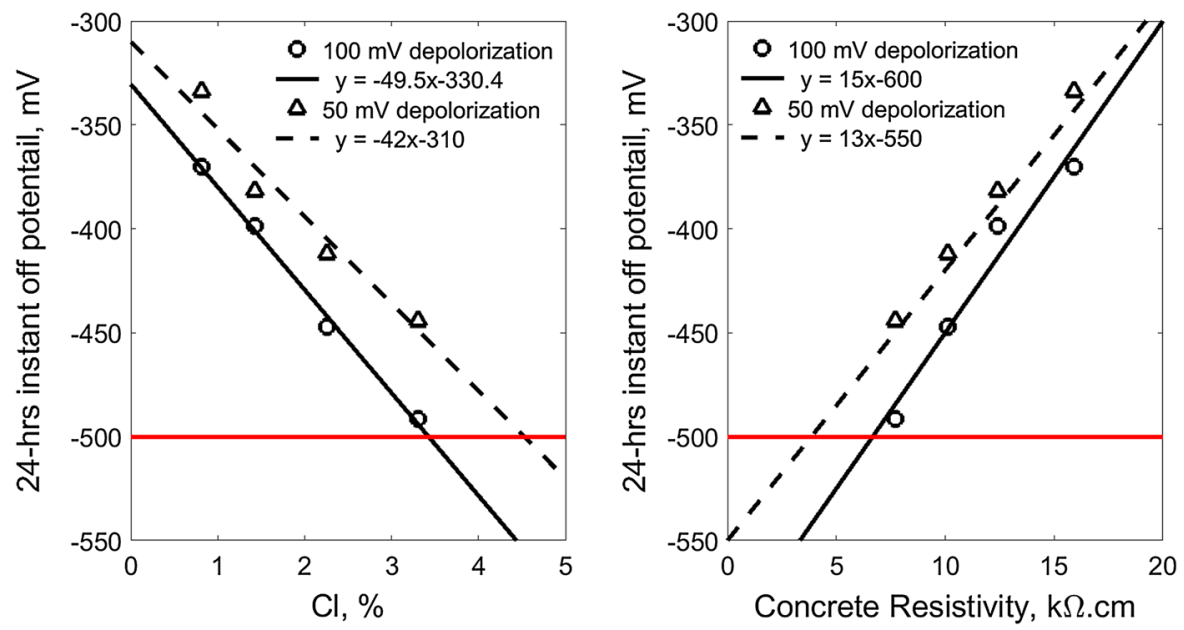

Fig. 11 The required 24-h CP instant-off potential for the $100 \mathrm{mV}$ and $50 \mathrm{mV}$ depolarization (4-h decay potential) versus chloride content and concrete resistivity (the horizontal lines indicate $-500 \mathrm{mV}$ instant-off potential)

obtained in this work can only provide the guidance for the reinforcements that have already been experiencing active corrosion, such as, for example, those in chloride contaminated concrete with a low $\mathrm{pH}$ pore solution.

2. All measurements are based on the hypothesis that corrosion on the rebars is homogeneously distributed, i.e. even if the corrosion might be localized on the microscopic scale, on a macroscopic scale there are no regions where corrosion is substantially more severe compared to others. In order to work under this assumption, in preparing specimens, efforts were made to enhance even chloride distribution in concrete by (1) adding $\mathrm{Cl}$ into mixing water as the most conventional measure [42-46] but also (2) curing samples in water containing the same amount of chlorides. The examination of the rebars after CP measurement had confirmed the corrosion took place on the whole exposed rebar surfaces.

\section{Conclusions}

This paper has produced a number of experimental data for CP performance on the reinforcement of Portland cement concrete exposed to chloride contamination under atmospheric condition. From the reported work, the following conclusions can be obtained:
1. A total chloride content of $0.31 \%$ by weight of cement or $17 \mathrm{k} \Omega \mathrm{cm}$ concrete electrical resisitivity may be set as a threshold for CP implementation to protect the reinforcements in Portland concrete from corrosion.

2. An instant-off potential of $-500 \mathrm{mV}$ with respect to $\mathrm{Ag} / \mathrm{AgCl} / 0.5 \mathrm{KCl}$ electrode can provide adequate protection, in relation to the $100 \mathrm{mV}$ depolarization criterion, for the reinforced concrete of up to $3.4 \%$ chloride contamination by weight of cement, or concrete resistivity is no less than $6.7 \mathrm{k} \Omega \mathrm{cm}$.

3. A clear correlation between $\mathrm{CP}$ current requirement and chloride content and concrete resistivity were obtained, and characterisation modelling has been suggested.

Acknowledgements This study was funded by the Iraqi Ministry of Higher Education and Scientific Research Scholarship Program.

\section{Compliance with ethical standards}

Conflict of interest The authors declare that they have no conflict of interest.

Open Access This article is distributed under the terms of the Creative Commons Attribution 4.0 International License (http:// creativecommons.org/licenses/by/4.0/), which permits unrestricted use, distribution, and reproduction in any medium, provided you give appropriate credit to the original author(s) and the source, provide a link to the Creative Commons license, and indicate if changes were made. 


\section{References}

1. Ahmad S (2003) Reinforcement corrosion in concrete structures, its monitoring and service life prediction-a review. Cem Concr Compos 25:459-471

2. Kendell K (1995) A five year review of the application of cathodic protection to various industrial concrete structures in the Arabian Gulf. In: Second regional concrete durability in the Arabian Gulf, Bahrain, pp 265-280

3. Buenfeld NR, Glass GK, Hassanein AM, Zhang J-Z (1998) Chloride transport in concrete subjected to electric field. J Mater Civ Eng 10:220-228

4. Verma SK, Bhadauria SS, Akhtar S (2014) Monitoring corrosion of steel bars in reinforced concrete structures. Sci World J 2014:957904

5. Popoola A, Olorunniwo O, Ige O (2014) Corrosion resistance through the application of anti-corrosion coatings. In: Aliofkhazraei M (ed) Developments in corrosion protection. InTech, pp 241-270. https://doi.org/10.5772/57420

6. Martínez I, Andrade C (2008) Application of EIS to cathodically protected steel: tests in sodium chloride solution and in chloride contaminated concrete. Corros Sci 50:2948-2958

7. Wilson K, Jawed M, Ngala V (2013) The selection and use of cathodic protection systems for the repair of reinforced concrete structures. Constr Build Mater 39:19-25

8. Christodoulou C, Glass G, Webb J, Austin S, Goodier C (2010) Assessing the long term benefits of Impressed Current Cathodic Protection. Corros Sci 52:2671-2679

9. Aperador W, Bautista-Ruiz J, Chunga K (2015) Determination of the efficiency of cathodic protection applied to alternative concrete subjected to carbonation and chloride attack. Int J Electrochem Sci 10:7073-7082

10. Muehlenkamp E, Koretsky M, Westall J (2005) Effect of moisture on the spatial uniformity of cathodic protection of steel in reinforced concrete. Corrosion 61:519-533

11. Kepler JL, Darwin D, Locke CE (2000) Evaluation of corrosion protection methods for reinforced concrete highway structures, Kansas department of transportation K-tran project No. Ku-99-6, University of Kansas centre for research, Inc. Lawrence. http://www2.ku.edu/ iri/ projects/corrosion/SM58.PDF

12. Pedeferri P (1996) Cathodic protection and cathodic prevention. Constr Build Mater 10:391-402

13. Zhu J-H, Miaochang Z, Ningxu H, Wei L, Feng X (2014) Electrical and mechanical performance of carbon fiber-reinforced polymer used as the impressed current anode material. Materials 7:5438-5453

14. Van Nguyen C, Lambert P, Mangat P, O'Flaherty F, Jones G (2012) The performance of carbon fibre composites as ICCP anodes for reinforced concrete structures. ISRN Corrosion 2012:1-9

15. Lambert P, Van Nguyen C, Mangat PS, O'Flaherty FJ, Jones G (2015) Dual function carbon fibre fabric strengthening and impressed current cathodic protection (ICCP) anode for reinforced concrete structures. Mater Struct 48:2157-2167

16. Chess PM, Broomfield JP (2013) Cathodic protection of steel in concrete and masonry, 2nd edn. CRC Press, USA
17. Cheung MMS, Cao C (2013) Application of cathodic protection for controlling macrocell corrosion in chloride contaminated RC structures. Constr Build Mater 45:199-207

18. NACE SP0290 (2007) Impressed current cathodic protection of reinforcing steel in atmospherically exposed concrete structures. In: NACE International, Houston, TX, USA

19. Takewaka K (1993) Cathodic protection for reinforcedconcrete and prestressed-concrete structures. Corros Sci 35:1617-1626

20. Shi X, Cross JD, Ewan L, Liu Y, Fortune K (2011) Replacing thermal sprayed zinc anodes on cathodically protected steel reinforced concrete bridges. Oregon Department of Transportation Research Section and Federal Highway Administration, Washington. http://www.trb.org/ BridgesOtherStructures/Blurbs/166080.aspx

21. BS EN ISO 12696 (2012) Cathodic protection of steel in concrete. In: British Standards Institution

22. Beamish S, El-Belbol S, Ngala V (2016) Maintenance of structural integrity using cathodic protection. Proc Inst Civ Eng Forensic Eng 169:72-80

23. Bertolini L, Elsener B, Pedeferri P, Redaelli E, Polder RB (2013) Corrosion of steel in concrete: prevention, diagnosis, repair, 2nd edn. Wiley, Germany

24. Teychenné DC, Franklin RE, Erntroy HC (1997) Design of normal concrete mixes, 2nd edn. Construction Research Communications Ltd, UK

25. Oleiwi H, Wang Y, Xiang N, Curioni M, Augusthus-Nelson L, Chen X, Shabalin I (2018) Electrical resistivity at varied water, chloride contents and porosity-an experimental study. Construction and Building Materials, submitted

26. ASTM C1152/C1152M (2012) Standard test method for acid-soluble chloride in mortar and concrete. In: ASTM International, West Conshohocken, PA, USA

27. Stern M, Geary AL (1957) Electrochemical polarization I. A theoretical analysis of the shape of polarization curves. J Electrochem Soc 104:56-63

28. Kupwade-Patil K, Allouche EN (2012) Examination of chloride-induced corrosion in reinforced geopolymer concretes. J Mater Civ Eng 25:1465-1476

29. Sathiyanarayanan S, Natarajan P, Saravanan K, Srinivasan S, Venkatachari G (2006) Corrosion monitoring of steel in concrete by galvanostatic pulse technique. Cem Concr Compos 28:630-637

30. Huang R, Chang J-J, Wu J-K (1996) Correlation between corrosion potential and polarization resistance of rebar in concrete. Mater Lett 28:445-450

31. Qiao G, Guo B, Ou J, Xu F, Li Z (2016) Numerical optimization of an impressed current cathodic protection system for reinforced concrete structures. Constr Build Mater 119:260-267

32. Zafeiropoulou T, Rakanta E, Batis G (2013) Carbonation resistance and anticorrosive properties of organic coatings for concrete structures. J Surf Eng Mater Adv Technol 3:67

33. Hornbostel K, Larsen CK, Geiker MR (2013) Relationship between concrete resistivity and corrosion rate-a literature review. Cem Concr Compos 39:60-72

34. Broomfield JP (2007) Corrosion of steel in concrete: understanding, investigation and repair, 2 nd edn. Taylor \& Francis, London 
35. Bertolini L, Bolzoni F, Gastaldi M, Pastore T, Pedeferri P, Redaelli E (2009) Effects of cathodic prevention on the chloride threshold for steel corrosion in concrete. Electrochim Acta 54:1452-1463

36. Morris W, Vico A, Vázquez M (2004) Chloride induced corrosion of reinforcing steel evaluated by concrete resistivity measurements. Electrochim Acta 49:4447-4453

37. Cavalier P, Vassie P (1981) Investigation and repair of reinforcement corrosion in a bridge deck. In: Institution of civil engineers, proceedings, $\mathrm{Pt} 1$

38. Langford P, Broomfield J (1987) Monitoring the corrosion of reinforcing steel. Constr Repair 1:32-36

39. Gonzalez J, Miranda J, Feliu S (2004) Considerations on reproducibility of potential and corrosion rate measurements in reinforced concrete. Corros Sci 46:2467-2485

40. Jeong J-A, Jin C-K, Chung W-S (2012) Tidal water effect on the hybrid cathodic protection systems for marine concrete structures. J Adv Concr Technol 10:389-394

41. Carmona J, Garcés P, Climent M (2015) Efficiency of a conductive cement-based anodic system for the application of cathodic protection, cathodic prevention and electrochemical chloride extraction to control corrosion in reinforced concrete structures. Corros Sci 96:102-111

42. Calero JC, Climent Llorca MA, Garcés Terradillos P (2017) Influence of different ways of chloride contamination on the efficiency of cathodic protection applied on structural reinforced concrete elements. J Electroanal Chem 793:8-17

43. Angst U, Elsener B, Larsen CK, Vennesland Ø (2009) Critical chloride content in reinforced concrete-a review. Cem Concr Res 39:1122-1138

44. Güneyisi E, Gesoğlu M, Karaboğa F, Mermerdaş K (2013) Corrosion behavior of reinforcing steel embedded in chloride contaminated concretes with and without metakaolin. Compos B Eng 45:1288-1295

45. Xu J, Yao W (2009) Current distribution in reinforced concrete cathodic protection system with conductive mortar overlay anode. Constr Build Mater 23:2220-2226

46. Hussain RR (2011) Influence of chloride ions and hot weather on isolated rusting steel bar in concrete based on NDT and electro-chemical model evaluation. NDT \& E Int 44:158-162 